NASA/TM-2011-217028

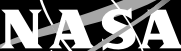

Attenuation of Scattered Thermal Energy Atomic Oxygen

Bruce A. Banks and Katelyn T. Seroka

Alphaport, Inc., Cleveland, Ohio

Jason B. McPhate

University of California, Berkeley, California

Sharon K. Miller

Glenn Research Center, Cleveland, Ohio 


\section{NASA STI Program . . . in Profile}

Since its founding, NASA has been dedicated to the advancement of aeronautics and space science. The NASA Scientific and Technical Information (STI) program plays a key part in helping NASA maintain this important role.

The NASA STI Program operates under the auspices of the Agency Chief Information Officer. It collects, organizes, provides for archiving, and disseminates NASA's STI. The NASA STI program provides access to the NASA Aeronautics and Space Database and its public interface, the NASA Technical Reports Server, thus providing one of the largest collections of aeronautical and space science STI in the world. Results are published in both non-NASA channels and by NASA in the NASA STI Report Series, which includes the following report types:

- TECHNICAL PUBLICATION. Reports of completed research or a major significant phase of research that present the results of NASA programs and include extensive data or theoretical analysis. Includes compilations of significant scientific and technical data and information deemed to be of continuing reference value. NASA counterpart of peer-reviewed formal professional papers but has less stringent limitations on manuscript length and extent of graphic presentations.

- TECHNICAL MEMORANDUM. Scientific and technical findings that are preliminary or of specialized interest, e.g., quick release reports, working papers, and bibliographies that contain minimal annotation. Does not contain extensive analysis.

- CONTRACTOR REPORT. Scientific and technical findings by NASA-sponsored contractors and grantees.
- CONFERENCE PUBLICATION. Collected papers from scientific and technical conferences, symposia, seminars, or other meetings sponsored or cosponsored by NASA.

- SPECIAL PUBLICATION. Scientific, technical, or historical information from NASA programs, projects, and missions, often concerned with subjects having substantial public interest.

- TECHNICAL TRANSLATION. Englishlanguage translations of foreign scientific and technical material pertinent to NASA's mission.

Specialized services also include creating custom thesauri, building customized databases, organizing and publishing research results.

For more information about the NASA STI program, see the following:

- Access the NASA STI program home page at http://www.sti.nasa.gov

- E-mail your question via the Internet to help@ sti.nasa.gov

- Fax your question to the NASA STI Help Desk at $443-757-5803$

- Telephone the NASA STI Help Desk at 443-757-5802

- Write to: NASA Center for AeroSpace Information (CASI) 7115 Standard Drive Hanover, MD 21076-1320 
NASA/TM-2011-217028

INA

Attenuation of Scattered Thermal Energy Atomic Oxygen

Bruce A. Banks and Katelyn T. Seroka

Alphaport, Inc., Cleveland, Ohio

Jason B. McPhate

University of California, Berkeley, California

Sharon K. Miller

Glenn Research Center, Cleveland, Ohio

Prepared for the

10th International Space Conference on Protection of Materials and Structures from the

Space Environment (ICPMSE-10J)

sponsored by the ITL, MDA, CSA, JAXA, and the Graduate School of Engineering, Kobe University

Bankoku-Shinryokan, Okinawa, Japan, June 12-17, 2011

National Aeronautics and

Space Administration

Glenn Research Center

Cleveland, Ohio 44135 
Trade names and trademarks are used in this report for identification only. Their usage does not constitute an official endorsement, either expressed or implied, by the National Aeronautics and Space Administration.

Level of Review: This material has been technically reviewed by technical management.

Available from

NASA Center for Aerospace Information 7115 Standard Drive

Hanover, MD 21076-1320
National Technical Information Service 5301 Shawnee Road Alexandria, VA 22312

Available electronically at http://www.sti.nasa.gov 


\title{
Attenuation of Scattered Thermal Energy Atomic Oxygen
}

\author{
Bruce A. Banks and Katelyn T. Seroka \\ Alphaport, Inc. \\ Cleveland, Ohio 44135 \\ Jason B. McPhate \\ University of California \\ Berkeley, California 94720 \\ Sharon K. Miller \\ National Aeronautics and Space Administration \\ Glenn Research Center \\ Cleveland, Ohio 44135
}

\begin{abstract}
The attenuation of scattered thermal energy atomic oxygen is relevant to the potential damage that can occur within a spacecraft which sweeps through atomic oxygen in low Earth orbit (LEO). Although there can be significant oxidation and resulting degradation of polymers and some metals on the external surfaces of spacecraft, there are often openings on a spacecraft such as telescope apertures, vents, and microwave cavities that can allow atomic oxygen to enter and scatter internally to the spacecraft. Atomic oxygen that enters a spacecraft can thermally accommodate and scatter to ultimately react or recombine on surfaces. The atomic oxygen that does enter a spacecraft can be scavenged by use of high erosion yield polymers to reduce its reaction on critical surfaces and materials. Polyoxymethylene and polyethylene can be used as effective atomic oxygen scavenging polymers.
\end{abstract}

\section{Introduction}

Spacecraft in low Earth orbit (LEO) sweep through atomic oxygen resulting in hyperthermal $(\sim 4.5 \mathrm{eV})$ atomic oxygen attack on ram facing surfaces. Although there can be significant oxidation and resulting degradation of polymers and some metals on the external surfaces of spacecraft, there can also be damage to materials and sensitive surfaces within a spacecraft if the atomic oxygen is allowed to enter. Atomic oxygen can enter spacecraft through openings such as telescope apertures, vents, and microwave cavities. The atomic oxygen that does enter will either react with organic or other reactive surfaces, reassociate to become chemically inactive diatomic oxygen, or lose its hyperthermal energy as it scatters off multiple surfaces and becomes thermally accommodated atomic oxygen (Refs. 1 to 3). This thermally accommodated atomic oxygen is still fully capable of reacting with materials even though its reaction probability is greatly reduced compared to hyperthermal atomic oxygen. Sensitive optical filters, optical sensors that operate on photoelectric effect principals, or microwave cavities can be compromised by the presence of a fluence of thermal energy atomic oxygen.

The objective of this investigation is to compare the degree to which scattered thermal energy atomic oxygen is attenuated by the material it scatters from. This is relevant to considerations of what materials may be best to have within a spacecraft to scavenge the atomic oxygen and to reduce its damage to sensitive materials and surfaces. 


\section{Apparatus and Procedure}

The experiments were conducted in radio frequency plasma ashers operating on air (Ref. 4). Kapton $\mathrm{H}$ polyimide witness samples were used to measure the flux of atomic oxygen inside and outside of scattering chambers. Drawings and photos of the three types of scattering chambers used include: an open-ended chamber (Fig. 1), a cylindrical Faraday cage chamber (Fig. 2), and two rectangular Faraday cage chambers (Fig. 3). In the first two scattering chamber configurations, the walls were lined with various test materials to assess the impact of the material's interaction with atomic oxygen. The atomic oxygen Kapton $\mathrm{H}$ effective flux within the scattering chambers were measured by means of mass loss of the Kapton $\mathrm{H}$ witness sample at the bottom of the chambers. Kapton $\mathrm{H}$ effective flux in a thermal energy plasma asher is the hyperthermal flux in LEO that produces the same rate of erosion of Kapton H. A comparison of flux inside-to-outside scattering chambers was made by placing $2.54 \mathrm{~cm}$ diameter by $0.0127 \mathrm{~cm}$ thick Kapton $\mathrm{H}$ witness samples inside and outside the chambers and comparing weight loss per area. Outside the scattering chambers $1.905 \mathrm{~cm}$ diameter Kapton $\mathrm{H}$ witness samples were used to measure the ratio of inside-to-outside effective flux. The open-ended chamber typically used $0.05 \mathrm{~mm}$ thick sample materials to line the cylinders that were $5.65 \mathrm{~cm}$ long by $2.61 \mathrm{~cm}$ inside diameter. The Faraday cage chamber used the same set of materials but was $1.56 \mathrm{~cm}$ long by $2.61 \mathrm{~cm}$ inside diameter.

The rectangular Faraday cage was used to assess the impact of various size inner lid openings on the mass loss of a Kapton $\mathrm{H}$ sample inside the cage.

The open-ended chamber (Fig. 1) allowed a greater flux of atomic oxygen, ions, electrons and UV radiation to enter the scattering chamber than the Faraday cage chamber (Fig. 2). The Faraday cage chamber prevented line of sight entrance of atomic oxygen, ions or electrons. To accomplish this, the Faraday cage utilized three aluminum half-circles as shown in Figure 2.
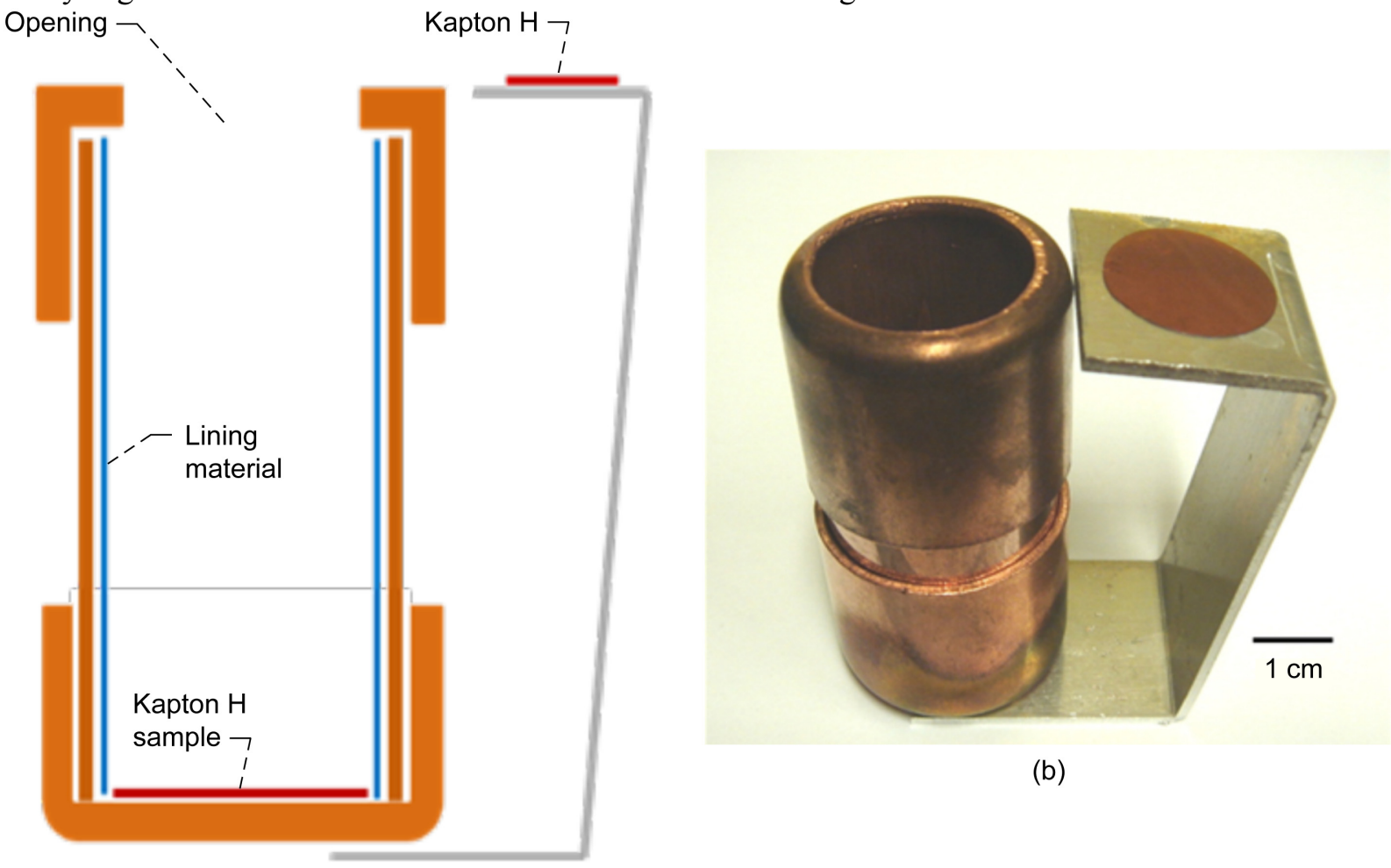

(b)

(a)

Figure 1.-Open-ended scattering chamber configuration used which allowed oxygen atoms, ions, electrons, and UV radiation to enter and interact with the chamber wall and Kapton at the bottom. (a) Section view (not to scale). (b) Photo. 


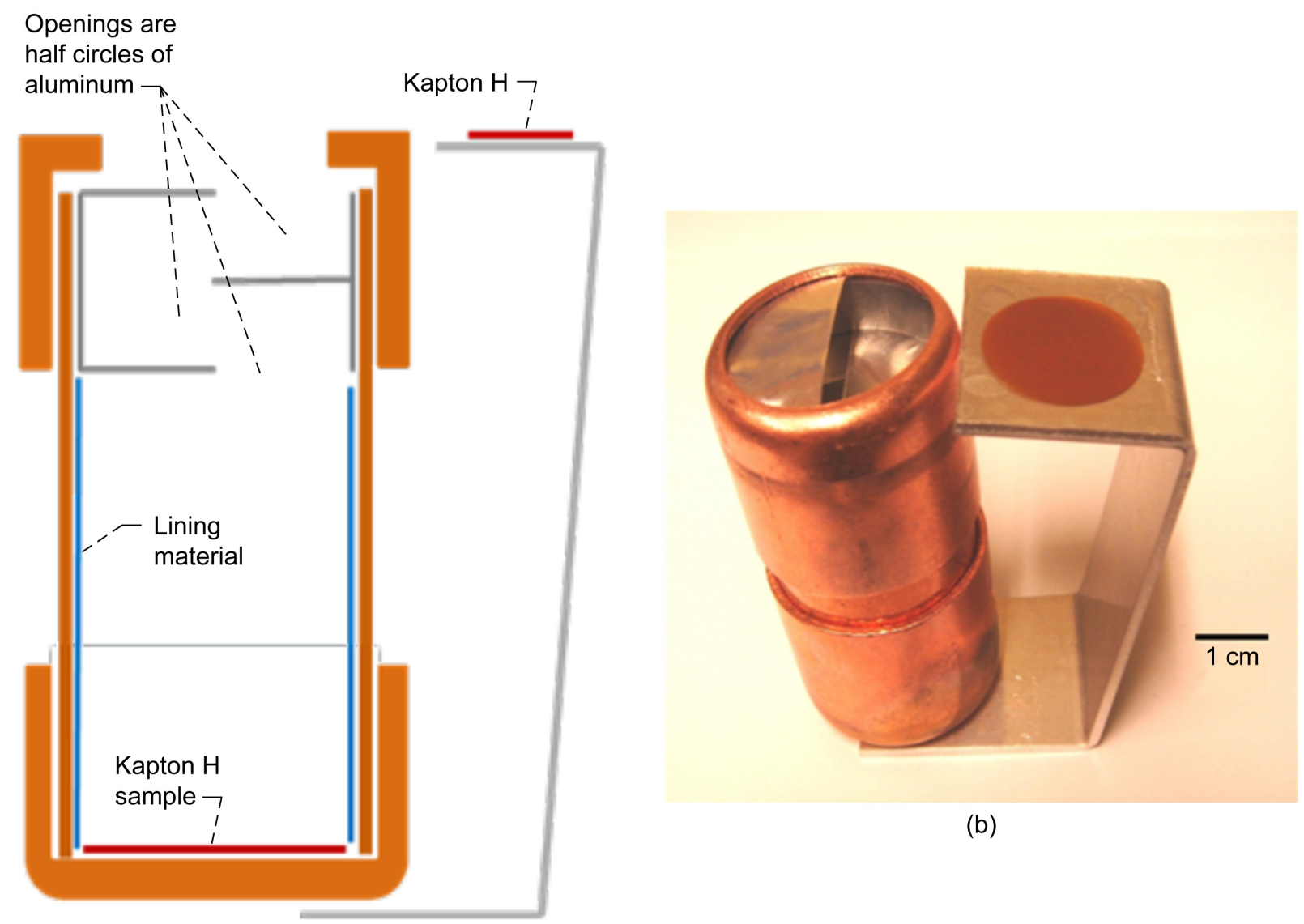

(a)

Figure 2.-Cylindrical Faraday cage chamber configuration with three aluminum half-circles that prevent the line of sight of to entrance of oxygen atoms, ions, and electrons into the chamber. (a) Section view (not to scale).

(b) Photo.

The rectangular Faraday cages were used to provide information on the attenuation of atomic oxygen due to varying the size of the opening into the cage as well as the fractional area of Kapton within the Faraday cage. The outer lid of the cage in Figure 3(a) and (b) measured approximately 15.2 by 11.4 by $2.1 \mathrm{~cm}$ high. This lid is shown upside down on the right side of Figure 3(b) and fit over the inner chamber which is shown on the left side of Figure 3(b). The inner chamber measured approximately 11.7 by 7.5 by $2.5 \mathrm{~cm}$ high and had four wires attached to it to hold the lid $0.7 \mathrm{~cm}$ above the chamber. A representative opening into the Faraday cage shown in Figure 3(a) and (b) can be seen as the small hole through the aluminum foil on the left side of the chamber. This opening was varied in size and in some cases two openings were used. The Faraday cage shown in Figure 3(c) and (d) was a simple hinged overlapping box that allowed covering the inner surface with varying amounts of Kapton to assess the attenuation of atomic oxygen due to fractional coverage of Kapton. The lids of both Faraday cages overlapped the lower chambers shown in Figure 3 thus preventing line of sight of plasma into the cages. Samples of $2.54 \mathrm{~cm}$ diameter Kapton $\mathrm{H}$ were placed on top of the lid and inside the chamber to assess the inside-to-outside mass loss ratio. 


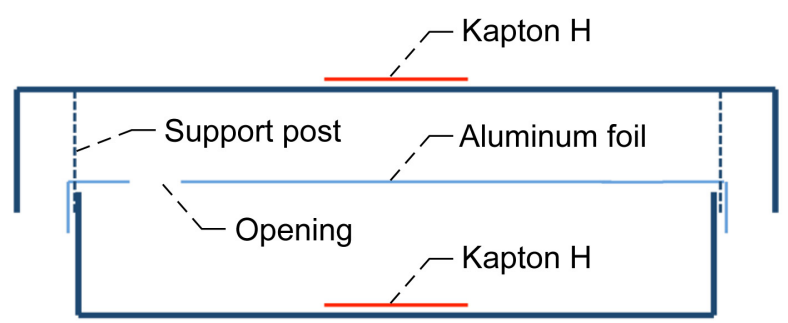

(a)

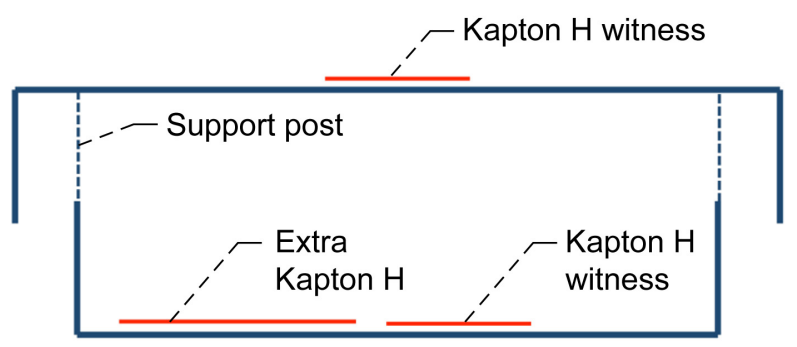

(c)

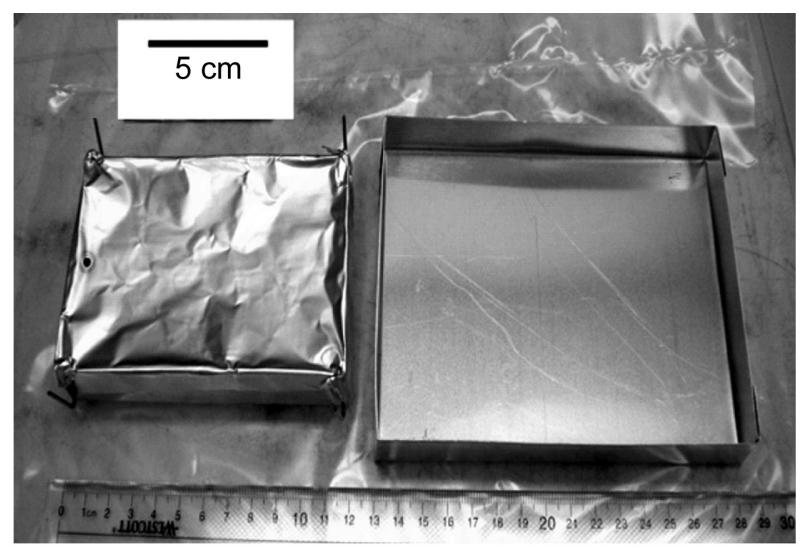

(b)

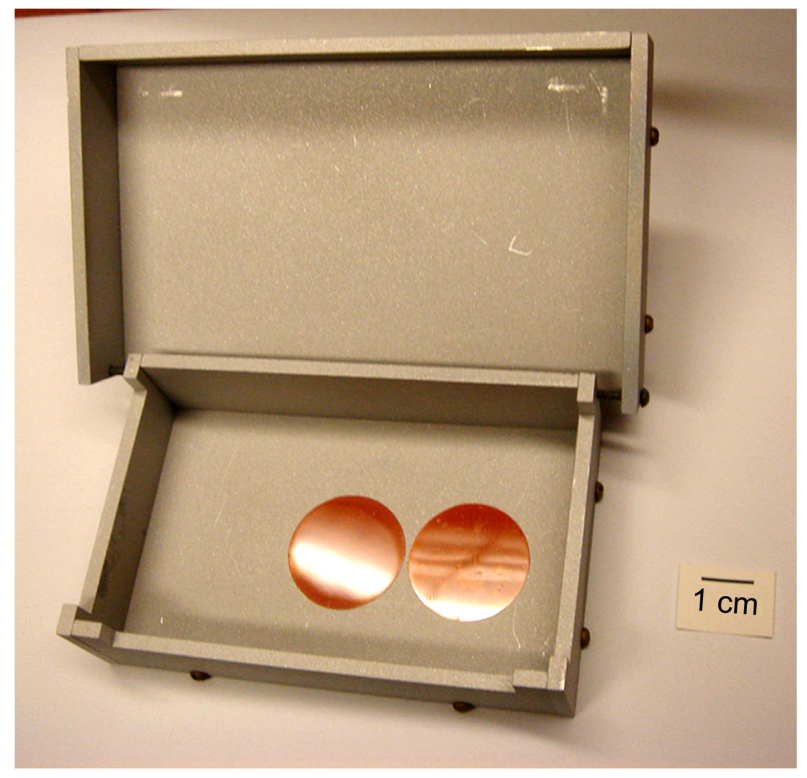

(d)

Figure 3.- Two rectangular Faraday cages made of aluminum. (a) Section view (not to scale) showing an all-aluminum chamber with a lid supported by four wire posts and separate inner chamber covered by aluminum foil. (b) Photo of cage (a). (c) Section view (not to scale) of a two part Faraday cage. (d) Photo of cage (c). 
The Kapton $\mathrm{H}$ witness samples were vacuum dehydrated for at least $48 \mathrm{hr}$ prior to all weight loss measurements in accordance with ASTM-E 2089-00, "Standard Practices for Ground Laboratory Atomic Oxygen Interaction Evaluation of Materials for Space Applications,"'(Ref. 4). The mass of the Kapton H witness samples was measured by averaging three mass measurements made within 5 min after removal from vacuum desiccation using a $10 \mu \mathrm{g}$ sensitivity Sartorius balance.

To assess the effects of various materials on the attenuation of the thermal energy atomic oxygen flux in the scattering chambers, linings of various metals, metal oxides, polymers, and graphite were used on the vertical sides of the chambers. The ratio of Kapton $\mathrm{H}$ effective flux, inside-to-outside, was measured by comparing the Kapton mass loss and correcting for area differences (in the case of open-ended and cylindrical Faraday cages). As can be seen by the Figures 1 to 3, the geometries of the scattering chambers were sufficiently different that direct comparison of atomic oxygen attenuation for any specific material cannot be made between the types of chambers. However, relative comparison of the differences from material to material can be made in terms of which sidewall causes the greatest attenuation in atomic oxygen for each configuration. The sidewall materials chosen for evaluation were: aluminum, copper, 300 series stainless steel, gold, silicon dioxide coated Kapton $\mathrm{H}$, flexible graphite made from pure, natural graphite flake (GRAFOIL), polyethylene, fluorinated propylene ethylene (FEP) Teflon, polyoxymethylene (POM), and chlorotrifluoroethylene (CTFE).

Thermal energy isotropic atomic oxygen behaves as a reactive gas where its partial pressure in a chamber determines the erosion rate of the polymer inside the chamber. The difference between the erosion rate inside the chamber and outside the chamber is influenced by the entry aperture area and the atomic oxygen partial pressure losses due to reaction with the wall and recombination within the chamber.

\section{Results and Discussion}

The flux in the asher was $\sim 5 \times 10^{15}$ atoms $/\left(\mathrm{cm}^{2} \mathrm{sec}\right)$ and the durations of exposures were typically $\sim 24$ to $68 \mathrm{hr}$. Thus, the fluence exposed to the outside Kapton $\mathrm{H}$ samples was at least $\sim 3.4 \times 10^{20}$ atoms $/\left(\mathrm{cm}^{2}\right)$.

The ratio of effective flux outside-to-inside for the open-ended scattering chamber is shown in Figure 4.

As can be seen, in general, the chamber lining materials that do not react with atomic oxygen tend to cause less attenuation of the atomic oxygen thus allowing a higher ratio of mass loss inside the scattering to outside the chambers. Copper reacts with atomic oxygen to form a nonprotecting brown $\mathrm{Cu}_{2} \mathrm{O}$ copper oxide (Ref. 5) that was found to spall from smooth copper surfaces. Thus, the copper lining of the open scattering chamber tended to reduce the amount of atomic oxygen mass loss. To prevent copper oxide from spalling, the copper surfaces were roughened by cross scratching the surface with rough sandpaper.

A comparison can be made between the above experimental results for $\mathrm{SiO}_{2}$ coated Kapton and a Monte Carlo computational model prediction (Ref. 3) with $\mathrm{SiO}_{2}$ walls. The Monte Carlo model is for a similar geometry but has sweeping or fixed arrival (at $45^{\circ}$ from normal) of hyperthermal LEO ram atomic oxygen rather than the isotropic thermal energy plasma of an asher environment. Slight differences exist in the geometry in that the Monte Carlo model assumes a square cross section well and the thermal energy plasma experiment uses a cylindrical scattering chamber. Figure 5 compares the ratio of Kapton $\mathrm{H}$ effective flux at the bottom of both scattering chambers to that outside the chambers.

As can be seen in Figure 5, the sweeping hyperthermal atomic oxygen in the Monte Carlo model predicts a higher erosion rate of Kapton $\mathrm{H}$ at the bottom of the scattering chamber than for the fixed $45^{\circ}$ arrival. This may be due to the fact that for a portion of the sweep angles, hyperthermal atomic oxygen can directly erode the Kapton $\mathrm{H}$ at the bottom of the chamber. For the fixed $45^{\circ}$ arrival only scattered, partial, or fully thermally accommodated atomic oxygen can react at the bottom. Because the reaction probability is much lower for the thermal energy than hyperthermal atomic oxygen, the erosion rate of the Kapton $\mathrm{H}$ at the bottom will also be lower. The experimental results for thermal energy isotropic plasmas indicate even more attenuation than for both Monte Carlo predictions involving hyperthermal atoms but reasonably close to that of the $45^{\circ} \mathrm{LEO}$ atoms. 


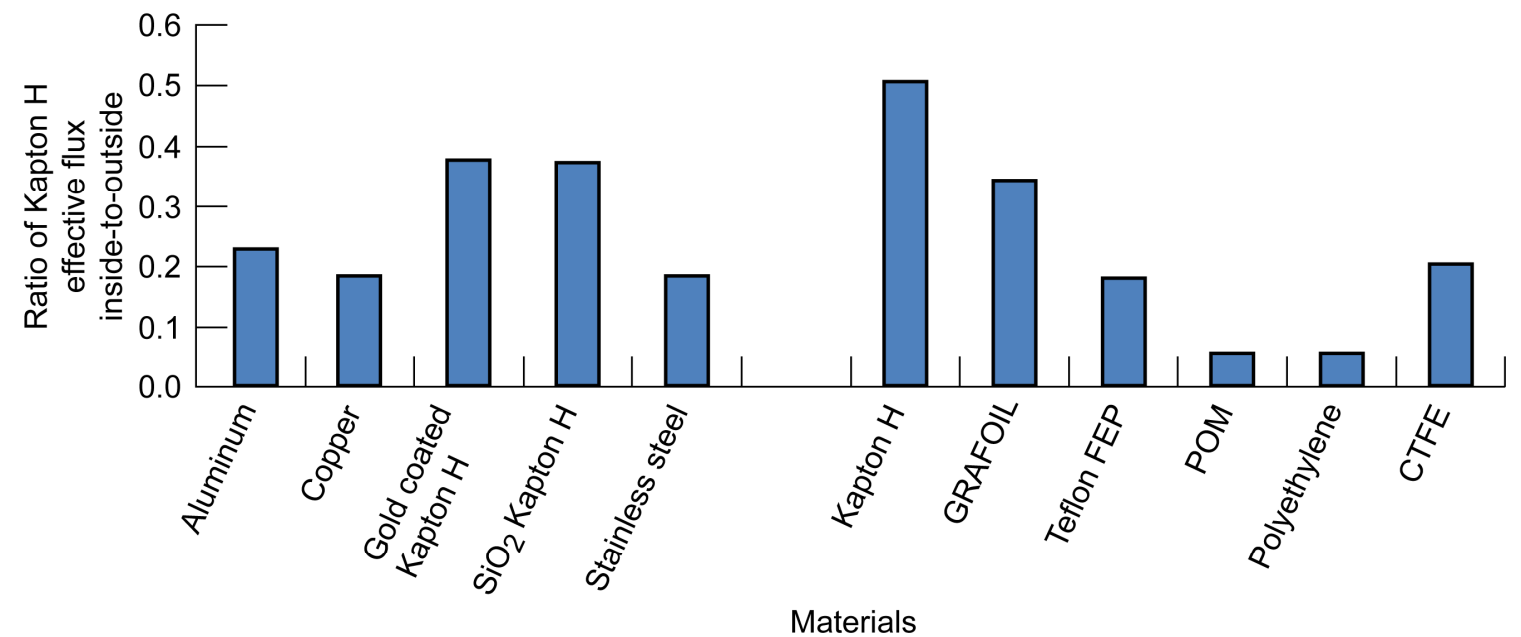

Figure 4.- Ratio of Kapton $\mathrm{H}$ mass loss inside-to-outside for the open-ended scattering chambers that are lined with various materials.

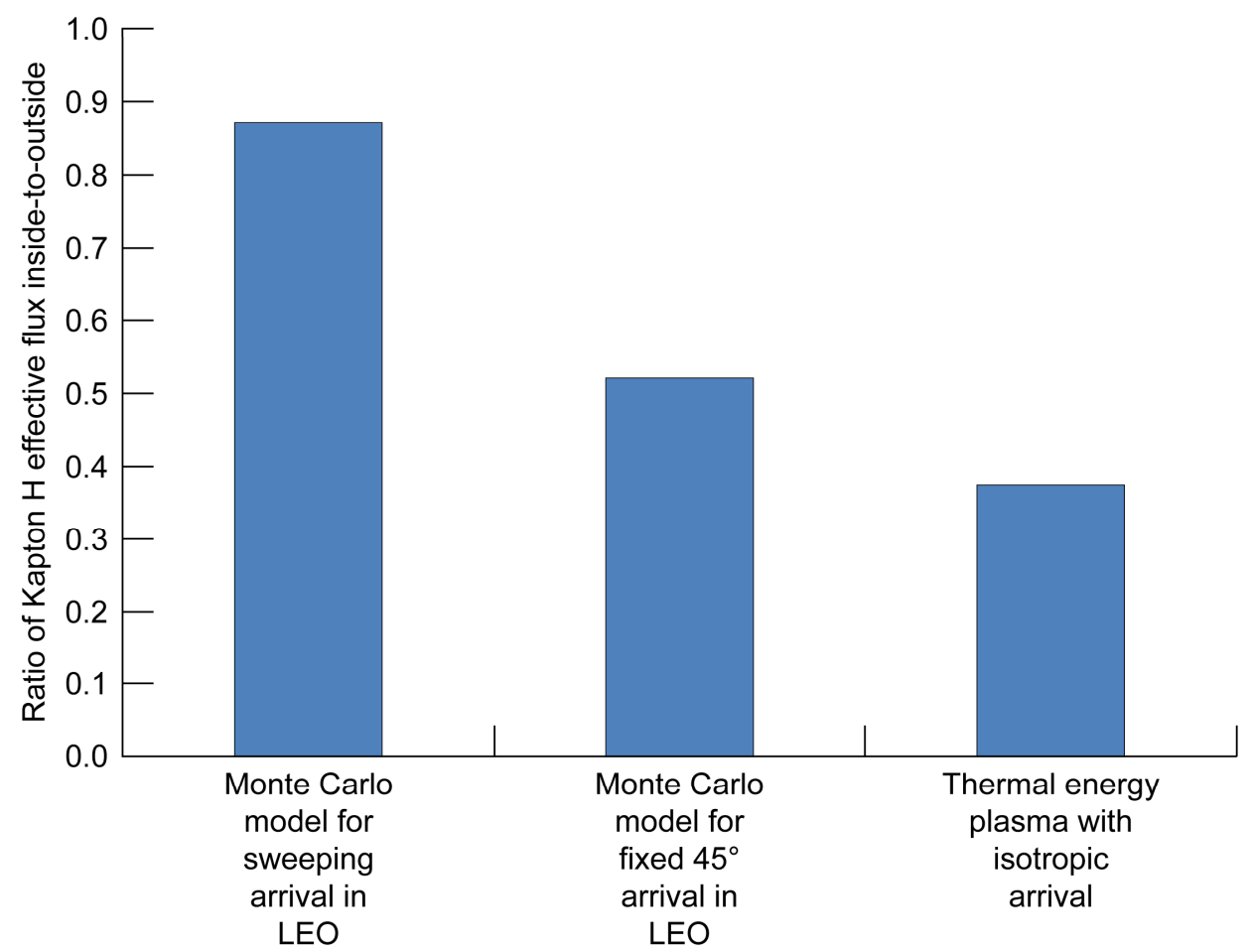

Figure 5.-Comparison of Kapton $\mathrm{H}$ effective flux inside-to-outside the open-ended scattering chambers with a length-to-width ratio of 2.16. 


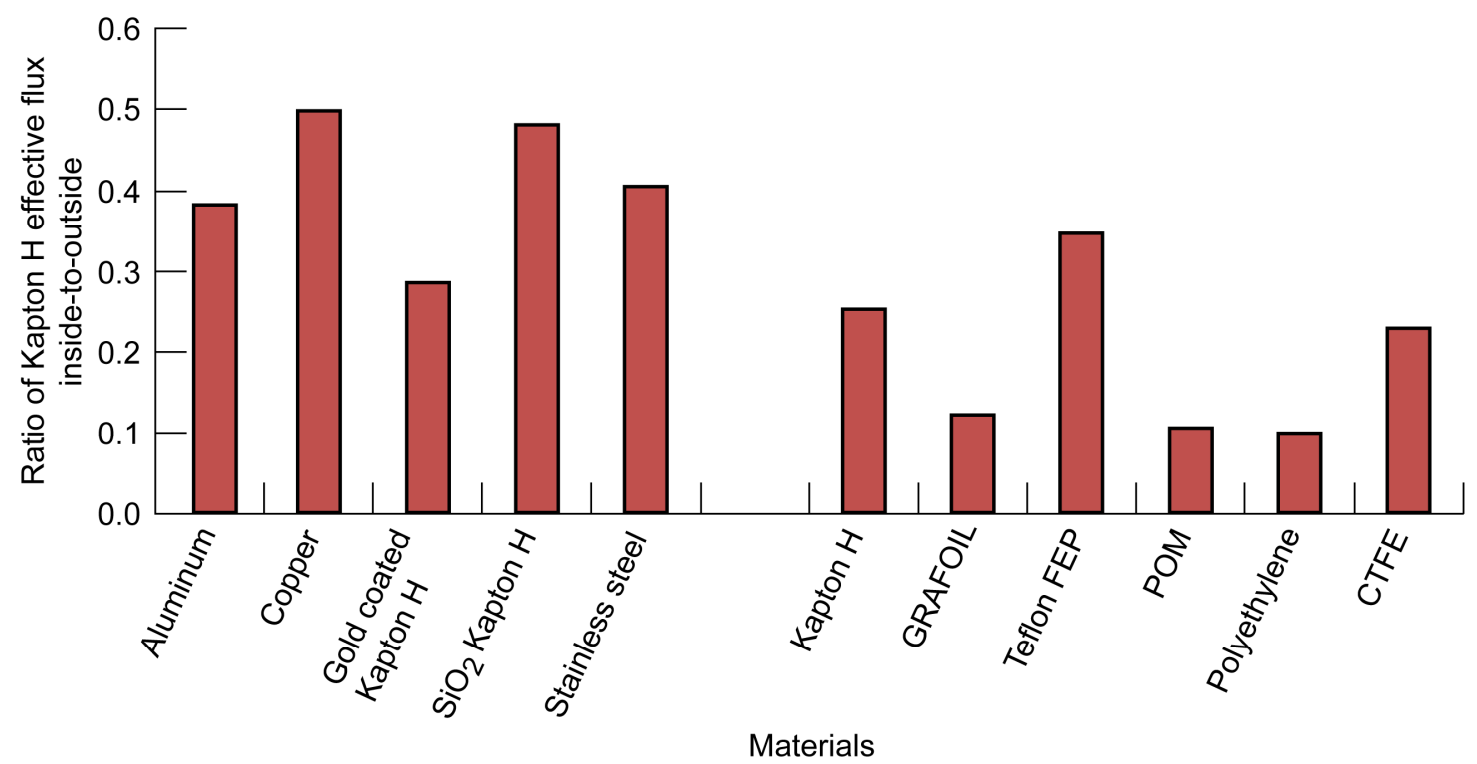

Figure 6.-Ratio of Kapton $\mathrm{H}$ effective flux inside-to-outside for Faraday cage scattering chambers that are lined with various materials.

The results of the Faraday cage scattering chamber are shown in Figure 6.

Although the geometries are quite different between the open and the Faraday scattering chambers, a comparison of ranking between materials indicates only minor differences in atomic oxygen attenuation. Again as in the open scattering chamber case, the chamber lining materials that do not react with atomic oxygen tend to prevent atomic oxygen attenuation. This leads to higher mass loss of the Kapton inside relative to outside the chambers. However, the best polymers, of those tested, to have in the Faraday cage to attenuate atomic oxygen are POM and polyethylene. Graphite from GRAFOIL is thought to be too friable to be safely used inside spacecraft.

It is also interesting to compare the amount of attenuation in atomic oxygen flux inside the Faraday cage as a function of the erosion yield measured in an asher environment. This was done assuming that the erosion yield for Kapton $\mathrm{H}$ is $3 \times 10^{-24} \mathrm{~cm}^{3} /$ atom (Refs. 6 and 7). Figure 7 is a plot of ratio of Kapton $\mathrm{H}$ effective flux inside a Faraday cage to outside the Faraday cage for various cage-lining materials as a function of the effective atomic oxygen erosion yield in an asher environment.

As can be seen, in general, those materials that have a high erosion yield in the thermal energy plasma environment tend to cause less erosion of the Kapton H witness samples within the Faraday cages. This is probably due to a reduction in the atomic oxygen density in the Faraday cage caused by greater reaction with the sidewall materials.

It is interesting to see the effect of the atomic oxygen entry area into the Faraday cage upon the erosion rate within the cage. The number density of atomic oxygen within a Faraday cage is dependent on flux impinging upon the cage, the area for the atomic oxygen entrance into the cage, and the losses within the cage. The losses include reaction and recombination with the wall materials and Kapton $\mathrm{H}$ sample at the base of the cage. Thus, the greater the area and erosion yield of materials that react with atomic oxygen, the more scavenging of atomic oxygen will occur. This will reduce the mass loss of Kapton $\mathrm{H}$ within the chamber relative to outside the chamber. If there is relatively little reaction with the walls of the chamber then the flux inside the chamber will be close to that outside the chamber. Only when the aperture into the chamber is sufficiently small will the losses within the chamber become significant enough to start showing reductions in polymer erosion relative to outside the chamber. Figure 8 compares the ratio of mass loss inside-to-outside Faraday cages as a function of the fractional area of the entrance aperture into the inside chamber plotted on a semi-log format. 


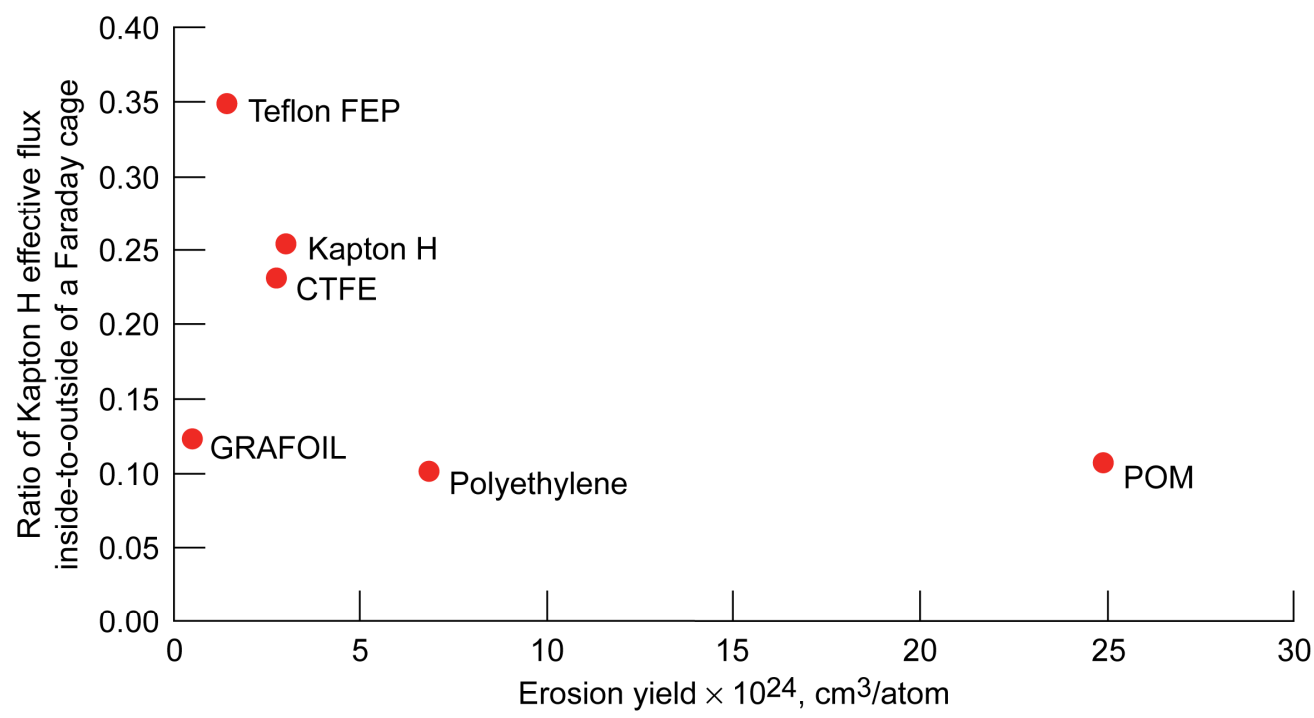

Figure 7.-Ratio of Kapton $\mathrm{H}$ effective flux inside-to-outside of a Faraday cage as a function of asher measured erosion yield.

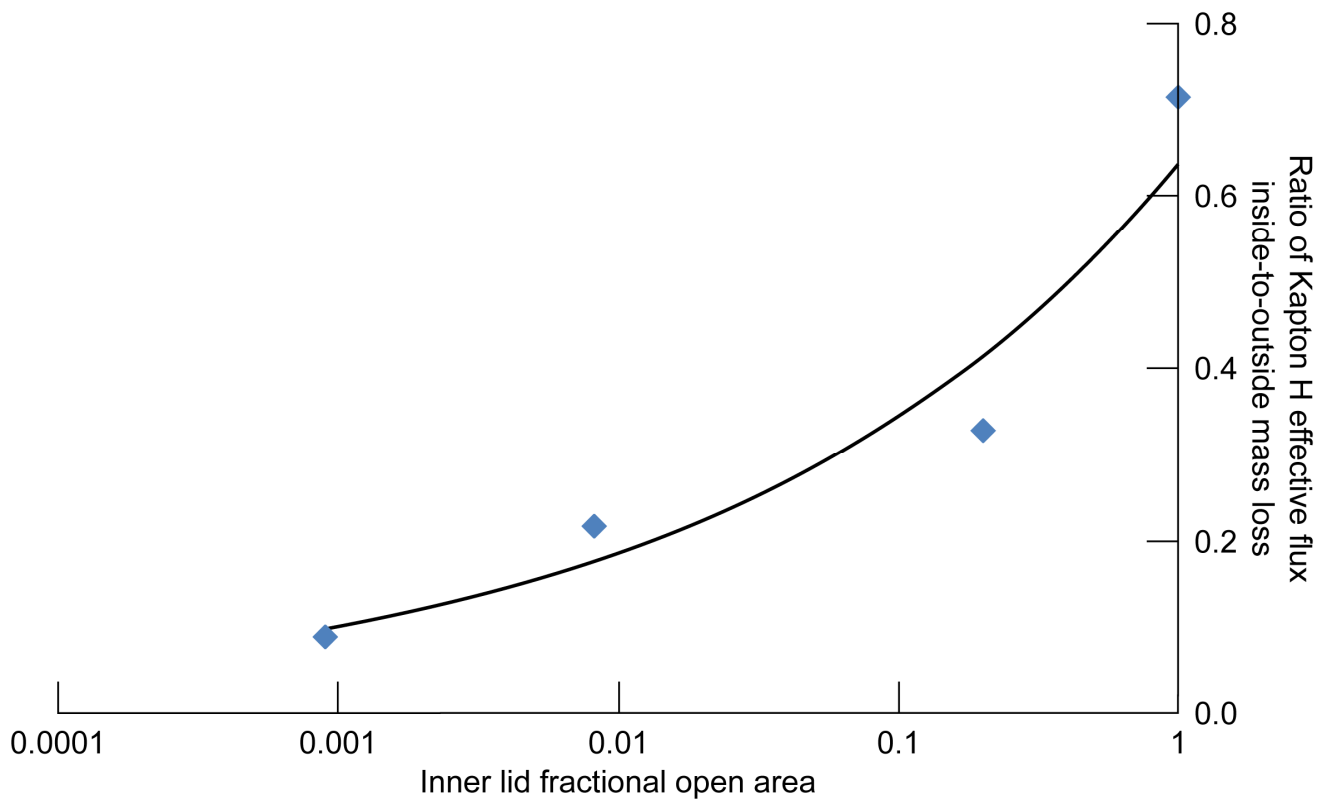

Figure 8.-Ratio of Kapton $\mathrm{H}$ effective flux inside-to-outside the Faraday cages as a function of the ratio of inner lid aperture to total inner lid area.

The data appears to have a simple power law dependence upon aperture area ratio. The ratio of mass loss of Kapton $\mathrm{H}$ inside-to-outside the Faraday cage is related to the ratio of aperture area to maximum inner lid area raised to the 0.268 power (shown as the curve fit line in Fig. 8). This results in a correlation coefficient of 0.95 . The reason the ratio of mass loss inside-to-outside is not one for an inner lid fractional area of one is because there is also attenuation of the flux as the atomic oxygen travels between the outer lid and the outside of the inner lid. As can be seen from Figure 8, an aperture of only 0.1 percent of the inner lid area still produces a flux within the chamber that is $\sim 10$ percent of that outside the Faraday cage. This implies that a small aperture on a spacecraft, which is oriented in the ram direction, has the potential to react a significant fraction of the ram fluence within the spacecraft. Even though the atomic oxygen 


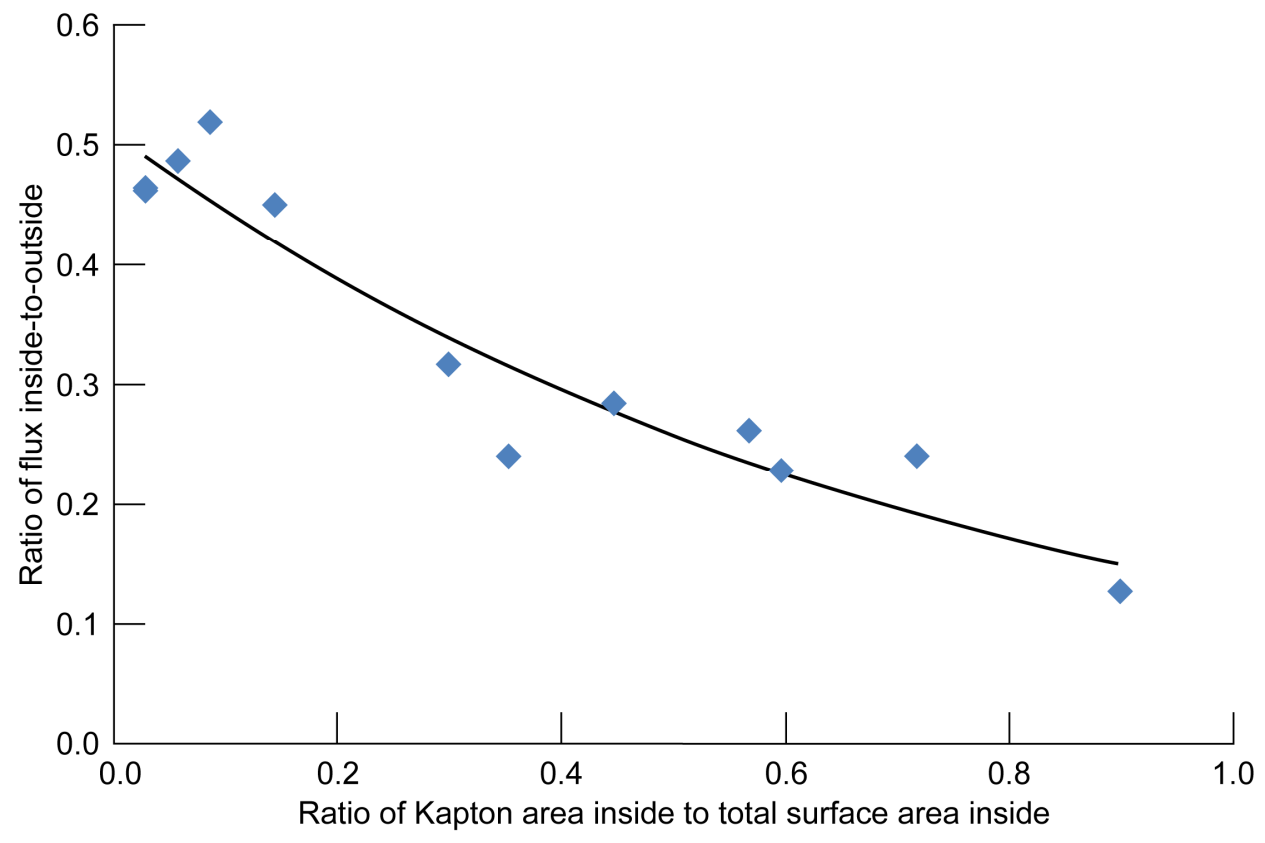

Figure 9.-Attenuation of atomic oxygen flux within a Faraday cage due the scavenging effect of varying amounts of Kapton $\mathrm{H}$ within the cage.

becomes thermally accommodated resulting in low reaction probabilities (Ref. 3), it can bounce around until it reacts with an organic or reactive surface. This can be overcome by using sacrificial polymers within the spacecraft to scavenge the atomic oxygen that scatters within it.

The resulting attenuation of atomic oxygen flux within a Faraday cage, due the scavenging effect of varying amounts of Kapton $\mathrm{H}$ within the cage, is shown in Figure 9 for the Faraday cage shown in Figure 3(c) and (d). This figure shows the dependence of the ratio of inside flux to outside flux upon the fraction of surface area inside the Faraday cage that is covered with Kapton H. The profile reasonably matches (a correlation coefficient of 0.9) and exponential dependence upon fractional coverage with Kapton. The results indicate that to reduce the flux by almost a factor of 5 within the cage, the Kapton fractional area coverage needs to be at least 90 percent. Thus, for effective scavenging of trapped atomic oxygen it is important to use a significant area coverage of polymers that have high reaction probabilities.

\section{Summary}

A ground laboratory investigation was conducted to assess the erosion rate of atomic oxygen that enters cavities in an effort to simulate telescope, vents, or microwave openings on spacecraft in low Earth orbit. To accomplish this, tests were conducted in RF plasma ashers to measure the ratio of mass loss of Kapton $\mathrm{H}$ polyimide placed inside and outside of three types of scattering chambers: an open-ended chamber which allowed a flux of atomic oxygen, ions, electrons and UV radiation to enter, a cylindrical Faraday cage chamber in which atomic oxygen could enter but very little ion, electron, or UV radiation, and a larger rectangular Faraday cage chamber was used to assess the effect of the atomic oxygen entry area into the Faraday cage upon the erosion rate within the cage.

The results of the investigation indicate that even small openings which allow ram atomic oxygen to enter a spacecraft can cause considerable reaction within the spacecraft to sensitive surfaces. This is in spite of the fact that the atomic oxygen thermally accommodates to have low reaction probabilities. The use of polymers within a spacecraft can contribute to scavenging of the atomic oxygen thus significantly reducing its flux. Tests were conducted on five metals or metal oxides, five polymers and graphite to assess their ability to reduce atomic oxygen flux within spacecraft. The results of the testing indicate that metals or metal oxides that do not react with atomic oxygen do little to reduce the flux of atomic oxygen 
within the spacecraft. However, copper which does not form a protective oxide and does react with atomic oxygen and reduces atomic oxygen flux. Polymers that have low atomic oxygen erosion yields tend not to scavenge atomic oxygen, whereas polymers that have high atomic oxygen erosion yields tend to scavenge atomic oxygen. Thus, use of atomic oxygen scavenging polymers that have high atomic oxygen erosion yields are recommended to minimize atomic oxygen attack within spacecraft that have openings to the low Earth orbital environment.

\section{References}

1. Banks, Bruce A., de Groh, Kim K., and Miller, Sharon K., "Low Earth Orbital Atomic Oxygen Interactions with Spacecraft Materials," NASA/TM-2004-213400 and paper presented at the Fall 2004 Meeting of the Materials Research Society, Boston Massachusetts, November 29December 3, 2004.

2. Banks, B.A., Miller, S.K., and de Groh, K., "Low Earth Orbital Atomic Oxygen Interactions with Materials," paper presented at the Second International Energy Conversion Engineering Conference sponsored by the American Institute of Aeronautics and Astronautics, AIAA-2004-5638, NASA/ TM-2004-213223, Providence, Rhode Island, August 16-19, 2004.

3. Banks, B., Miller, S., de Groh, K., and Demko, R., "Scattered Atomic Oxygen Effects on Spacecraft Materials," NASA/TM-2003-212484, June 2003 and Proceedings of the 9th International Symposium on Materials in a Space Environment, Noordwijk, The Netherlands, June 16-20, 2003, ESA SP-540, September 2003.

4. ASTM E 2089-00, "Standard Practices for Ground Laboratory Atomic Oxygen Interaction Evaluation of Materials for Space Applications," June 2000.

5. Silverman, E., "Space Environmental Effects on Spacecraft LEO Materials Selection Guide," NASA Contractor Report 4661, August 1995, section 6.2.2.

6. de Groh, K.K., Banks, B.A., McCarthy, C.E., Rucker, R.N., Roberts, L.M., and Berger, L.A., "MISSE 2 PEACE Polymers Atomic Oxygen Erosion Experiment on the International Space Station," Journal of High Performance Polymers, vol. 20, no. 4/5, August/October 2008.

7. Stambler, A.H., Inoshita, K.E., Roberts, L.M., Barbagallo, C.E., de Groh, K.K., Banks, B.A., "Ground-Laboratory to In-Space Atomic Oxygen Correlation for the PEACE Polymers," Proceedings of the 9th International Conference on Protection of Materials and Structures From Space Environment, Toronto, Canada May 20-23, 2008. 


\begin{tabular}{|c|c|c|}
\hline \multicolumn{2}{|c|}{ REPORT DOCUMENTATION PAGE } & $\begin{array}{l}\text { Form Approved } \\
\text { OMB No. 0704-0188 }\end{array}$ \\
\hline \multicolumn{3}{|c|}{ 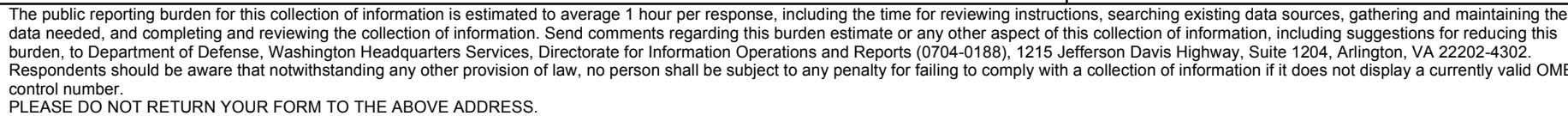 } \\
\hline $\begin{array}{l}\text { 1. REPORT DATE (DD-MM-YYYY) } \\
01-04-2011\end{array}$ & $\begin{array}{l}\text { 2. REPORT TYPE } \\
\text { Technical Memorandum }\end{array}$ & 3. DATES COVERED (From - To) \\
\hline \multirow{3}{*}{\multicolumn{2}{|c|}{$\begin{array}{l}\text { 4. TITLE AND SUBTITLE } \\
\text { Attenuation of Scattered Thermal Energy Atomic Oxygen }\end{array}$}} & 5a. CONTRACT NUMBER \\
\hline & & 5b. GRANT NUMBER \\
\hline & & 5c. PROGRAM ELEMENT NUMBER \\
\hline \multirow{3}{*}{\multicolumn{2}{|c|}{$\begin{array}{l}\text { 6. AUTHOR(S) } \\
\text { Banks, Bruce, A.; Seroka, Katelyn, T.; McPhate, Jason, B.; Miller, Sharon, K. }\end{array}$}} & 5d. PROJECT NUMBER \\
\hline & & 5e. TASK NUMBER \\
\hline & & $\begin{array}{l}\text { 5f. WORK UNIT NUMBER } \\
\text { WBS } 825080.04 .02 .30 .17\end{array}$ \\
\hline \multicolumn{2}{|c|}{$\begin{array}{l}\text { 7. PERFORMING ORGANIZATION NAME(S) AND ADDRESS(ES) } \\
\text { National Aeronautics and Space Administration } \\
\text { John H. Glenn Research Center at Lewis Field } \\
\text { Cleveland, Ohio 44135-3191 }\end{array}$} & $\begin{array}{l}\text { 8. PERFORMING ORGANIZATION } \\
\text { REPORT NUMBER } \\
\text { E-17693 }\end{array}$ \\
\hline \multirow{2}{*}{\multicolumn{2}{|c|}{$\begin{array}{l}\text { 9. SPONSORING/MONITORING AGENCY NAME(S) AND ADDRESS(ES) } \\
\text { National Aeronautics and Space Administration } \\
\text { Washington, DC 20546-0001 }\end{array}$}} & $\begin{array}{l}\text { 10. SPONSORING/MONITOR'S } \\
\text { ACRONYM(S) } \\
\text { NASA }\end{array}$ \\
\hline & & $\begin{array}{l}\text { 11. SPONSORING/MONITORING } \\
\text { REPORT NUMBER } \\
\text { NASA/TM-2011-217028 }\end{array}$ \\
\hline \multicolumn{3}{|c|}{$\begin{array}{l}\text { 12. DISTRIBUTION/AVAILABILITY STATEMENT } \\
\text { Unclassified-Unlimited } \\
\text { Subject Categories: } 23 \text { and } 27 \\
\text { Available electronically at http://www.sti.nasa.gov } \\
\text { This publication is available from the NASA Center for AeroSpace Information, 443-757-5802 }\end{array}$} \\
\hline
\end{tabular}

\section{SUPPLEMENTARY NOTES}

\section{ABSTRACT}

The attenuation of scattered thermal energy atomic oxygen is relevant to the potential damage that can occur within a spacecraft which sweeps through atomic oxygen in low Earth orbit (LEO). Although there can be significant oxidation and resulting degradation of polymers and some metals on the external surfaces of spacecraft, there are often openings on a spacecraft such as telescope apertures, vents, and microwave cavities that can allow atomic oxygen to enter and scatter internally to the spacecraft. Atomic oxygen that enters a spacecraft can thermally accommodate and scatter to ultimately react or recombine on surfaces. The atomic oxygen that does enter a spacecraft can be scavenged by use of high erosion yield polymers to reduce its reaction on critical surfaces and materials. Polyoxymethylene and polyethylene can be used as effective atomic oxygen scavenging polymers.

\section{SUBJECT TERMS}

Atomic oxygen; low Earth orbit (LEO); Spacecraft polymer

\begin{tabular}{|c|c|c|c|c|c|}
\hline \multicolumn{3}{|c|}{ 16. SECURITY CLASSIFICATION OF: } & \multirow{2}{*}{$\begin{array}{l}\text { 17. LIMITATION OF } \\
\text { ABSTRACT } \\
\text { UU }\end{array}$} & \multirow{2}{*}{$\begin{array}{l}\text { 18. NUMBER } \\
\text { OF } \\
\text { PAGES } \\
16\end{array}$} & \multirow{2}{*}{$\begin{array}{l}\text { 19a. NAME OF RESPONSIBLE PERSON } \\
\text { STI Help Desk (email:help@ } \text { sti.nasa.gov) } \\
\text { 19b. TELEPHONE NUMBER (include area code) } \\
\text { 443-757-5802 }\end{array}$} \\
\hline $\begin{array}{l}\text { a. REPORT } \\
U\end{array}$ & $\begin{array}{l}\text { b. ABSTRACT } \\
U\end{array}$ & $\begin{array}{l}\text { c. THIS } \\
\text { PAGE } \\
\text { U }\end{array}$ & & & \\
\hline
\end{tabular}



